\title{
ANALISIS MENGENAI PROBLEMATIKA YANG DIHADAPI KARYAWAN WANITA DI BIDANG PERHOTELAN
}

\author{
Maria Pia Adiati \\ Hotel Management Department, Faculty of Economic dan Communication, BINUS University \\ Jln. K.H. Syahdan No. 9, Palmerah, Jakarta Barat 11480 \\ mia_pia_adiati@hotmail.com
}

\begin{abstract}
Nowadays it is seen that women work in every line of work. This is also clearly seen in tourism industry and particularly in hotel industry. Many positions in hotel are held by women. These women have big participation in running the hotel industry while they have another task as a housewife while working. It is interested to analyze the problems faced by the women who work in the hotel since it relates to the nature of woman such has pregnant, to give birth, and to breast-feed the baby. The nature of woman must not be forgotten eventhough she is working and the hotel management should give attention to this nature since it relates to the daily hotel operational where the woman employee is involved in it.
\end{abstract}

Keywords: problematics, the nature of woman

\begin{abstract}
ABSTRAK
Pada masa sekarang, emansipasi wanita sudah sangat jelas terlihat di berbagai sektor pekerjaan. Di industri pariwisata terutama di industri perhotelan pun juga tampak terlihat sangat nyata. Banyak posisi di bidang perhotelan yang dipegang oleh wanita. Wanita berpartisipasi dalam menggerakkan industri perhotelan walaupun wanita mempunyai tugas yang tidak mudah karena merangkap sebagai ibu rumah tangga yang sambil bekerja. Problematika yang dihadapi wanita dalam menjalankan tugasnya di bidang perhotelan menarik untuk dianalisis karena berhubungan dengan kodrat seorang wanita seperti mengandung, melahirkan dan menyusui. Jadi walaupun para wanita tetap bekerja dalam bidang perhotelan, tetapi kodrat seorang wanita tidak boleh dilupakan dan pihak manajemen hotel juga harus tetap memperhatikan kodrat ini karena berhubungan dengan hotel dalam menjalankan operasionalnya dimana didalamnya banyak terdapat karyawan wanita.
\end{abstract}

Kata kunci: problematika, kodrat wanita 


\section{PENDAHULUAN}

Emansipasi wanita adalah hal penting yang sudah digerakkan sejak lama, dan sampai saat ini sangat terlihat hasilnya dalam semua sektor pekerjaan. Sejarah mencatat emansipasi wanita di Indonesia dimulai sejak jaman Ibu R.A. Kartini yang memperjuangkan agar wanita tidak hanya tinggal di rumah mengurus rumah tangga, tetapi wanita juga bisa berkembang di luar rumah.

Di Indonesia, fenomena mengenai emansipasi wanita juga diperkuat oleh peraturan menteri negara dan peranan wanita. Di dunia internasional seperti PBB juga dicermati mengenai kesetaraan gender dan emansipasi wanita. Dari kedua institusi besar seperti PBB dan pemerintah yang menyikapi masalah emansipasi wanita dan peranannya, maka bisa dilihat bahwa dunia pun mengakui bahwa wanita juga mempunyai hak yang sama dengan laki-laki dalam hal bekerja. Akan tetapi, mengingat wanita mempunyai suatu kodrat yang tidak bisa dilawan seperti mengandung, melahirkan, dan menyusui, maka perlu disikapi juga bahwa perlu aturan yang jelas dari pemerintah dan perusahaan tempat bekerja serta pengertian dari rekan kerja karyawan wanita saat karyawan wanita ini sedang di masa mengandung, melahirkan, dan menyusui.

Hingga saat ini, sudah tampak nyata bahwa wanita bekerja di hampir segala sektor pekerjaan, termasuk di sektor pekerjaan yang pada masa dulu dianggap hanya untuk pekerjaan laki-laki. Menurut catatan BPS, wanita sudah masuk dalam segala sisi pekerjaan, seperti: sektor primer yaitu sektor pertanian, sektor sekunder yaitu sektor industri, dan sektor tersier yaitu sektor perdagangan, hotel, dan restoran (Sumber: BPS.go.id). Dari ketiga sektor ini, pasti ada tenaga kerja wanita, walaupun dengan persentase yang berbeda-beda. Hal ini menunjukkan bahwa pada era milenium ini, wanita sudah terlibat banyak di segala lini dan segala posisi.

Di dunia perhotelan pun juga banyak tenaga kerja wanita yang bekerja pada bidang ini. Di hotel kita bisa lihat hampir pasti ada tenaga kerja wanita dalam setiap divisi di hotel tersebut, tidak terkecuali divisi sekuriti (pengamanan). Jaman dahulu mungkin divisi sekuriti hanya didominasi oleh laki-laki, tetapi sekarang sudah banyak wanita yang menjadi sekuriti. Terlepas dari apakah sekuriti wanita ini merupakan karyawan outsourceing hotel ataupun karyawan tetap, sekuriti wanita ini bekerja untuk hotel tersebut.

Di bidang culinary terutama bagian dapur (kitchen department), juga banyak ditemukan chef wanita walaupun memang jumlahnya kecil. Yang banyak terlihat adalah chef laki-laki, tetapi bukan berarti chef wanita tidak ada. Bagian dapur identik dengan laki-laki. Hal ini bukan karena diskriminasi gender, tetapi lebih kepada keadaan di dapur dimana peralatan masaknya kebanyakan besar dan berat.

Namun ada divisi di hotel yang memang biasanya diisi oleh wanita seperti bagian Guest Relation Officer (GRO) yang berada di bawah Front Office Department. Tugas dari GRO adalah menyambut tamu VIP pada saat kedatangan dan mengurus tamu VIP selama tinggal di hotel tersebut. Posisi ini identik dengan wanita karena dianggap wanita yang lebih pas untuk menyambut tamu VIP karena lebih luwes.

Dengan segala tipikalnya pada masing-masing divisi perhotelan, karyawan wanita mempunyai problematika tersendiri. Menarik untuk diketahui problematika apa saja yang dialami, sehingga pihak manajemen bisa mengambil kebijakan yang tepat agar tidak muncul konflik dalam operasional hotel sehari-hari. Ataupun munculnya diskriminasi terhadap karyawan wanita yang dapat mengakibatkan mundurnya karyawan wanita tersebut dari hotel, sehingga mengakibatkan hotel kehilangan aset dalam menjalankan operasionalnya. 
Penelitian ini bertujuan untuk mengetahui problematika yang dihadapi karyawan wanita di bidang perhotelan. Dan jika mungkin, ada saran yang berguna bagi pihak manajemen sehingga bisa memberi kepuasan kerja lebih bagi karyawan wanita.

\section{METODE PENELITIAN}

Penelitian ini menggunakan metode kualitatif yaitu mengumpulkan data dari buku, jurnal dan peraturan pemerintah serta observasi selama masih bekerja di hotel . Penelitian kualitatif ini akan mencari saran apa yang bisa dihasilkan untuk lebih mengayomi wanita dalam menjalankan tugas sebagai karyawan tetapi juga tetap menghargai wanita dalam menjalankan kodratnya.

\section{HASIL DAN PEMBAHASAN}

\section{Paradigma Mengenai Emansipasi Wanita}

Dilihat dari sejarah, perhatian dunia secara formal mengenai persamaan antara lelaki dan perempuan sudah dimulai pada tahun 1948 melalui suatu deklarasi yang disebut sebagai The Universal Declaration of Human Rights (Deklarasi Universal Hak Asasi Manusia), oleh Perserikatan BangsaBangsa (PBB), dan tahun 1976 dilengkapi menjadi The International Bill of Human Rights (Pernyataan Hak Asasi Manusia). Dalam prakatanya Presiden Amerika pada saat itu, Jimmy Carter, menyatakan bahwa Piagam PBB berbicara tentang keyakinan pada hak asasi manusia yang fundamental, pada martabat dan penghargaan manusia, pada persamaan hak laki-laki dan perempuan dan bangsa-bangsa besar dan kecil (Heraty, 1999).

Setelah lulus dari Sekolah Dasar ia tidak diperbolehkan melanjutkan sekolah ke tingkat yang lebih tinggi oleh orangtuanya. Ia dipingit sambil menunggu waktu untuk dinikahkan. Kartini kecil sangat sedih dengan hal tersebut, ia ingin menentang tapi tak berani karena takut dianggap anak durhaka. Untuk menghilangkan kesedihannya, ia mengumpulkan buku-buku pelajaran dan buku ilmu pengetahuan lainnya yang kemudian dibacanya di taman rumah dengan ditemani pembantunya.

Akhirnya, membaca menjadi kegemarannya, tiada hari tanpa membaca. Semua buku, termasuk surat kabar dibacanya. Kalau ada kesulitan dalam memahami buku-buku dan surat kabar yang dibacanya, ia selalu menanyakan kepada Bapaknya. Melalui buku inilah, Kartini tertarik pada kemajuan berpikir wanita Eropa (Belanda, yang waktu itu masih menjajah Indonesia). Timbul keinginannya untuk memajukan wanita Indonesia. Wanita tidak hanya di dapur tetapi juga harus mempunyai ilmu. Ia memulai dengan mengumpulkan teman-teman wanitanya untuk diajarkan tulismenulis dan ilmu pengetahuan lainnya. Di tengah kesibukannya, ia tidak berhenti membaca dan juga menulis surat dengan teman-temannya yang berada di negeri Belanda. Tak berapa lama ia menulis surat pada Mr. J.H. Abendanon. Ia memohon diberikan beasiswa untuk belajar di negeri Belanda.

Beasiswa yang didapatkannya tidak sempat dimanfaatkan Kartini karena ia dinikahkan oleh orangtuanya dengan Raden Adipati Joyodiningrat. Setelah menikah, ia ikut suaminya ke daerah Rembang. Suaminya mengerti dan ikut mendukung Kartini untuk mendirikan sekolah wanita. Berkat kegigihannya, Kartini berhasil mendirikan Sekolah Wanita di Semarang, Surabaya, Yogyakarta, Malang, Madiun, Cirebon, dan daerah lainnya. Nama sekolah tersebut adalah "Sekolah Kartini”.

Berkat RA Kartini, paradigma bahwa wanita hanya bisa berkarya di rumah sangat berubah. Dan hasilnya sangat terasa pada masa ini. Wanita bisa bekerja dan bahkan menduduki puncak pimpinan dari suatu perusahaan maupun mempunyai usaha sendiri, dimana ia bisa tetap mengurus rumah tangganya sambil bekerja di rumah. 


\section{Problematika bagi Karyawan Wanita secara Umum}

Dalam menjalankan pekerjaannya di hotel, para karyawan wanita baik yang belum menikah maupun yang sudah menikah mempunyai problematika tersendiri. Problematika umum yang dihadapi oleh karyawan wanita adalah sebagai berikut.

\section{Jam kerja yang mengikuti sistem shift}

Waktu kerja di hotel untuk divisi yang berhubungan langsung untuk melayani tamu (front liner) mengikuti jam kerja shift bukan office hour (office hour hanya untuk bagian yang tidak melayani tamu langsung seperti bagian keuangan atau sales and marketing). Adapun shift di hotel adalah sebagai berikut.

Shift pagi $\quad$ : pukul 06.00-pukul 15.00 atau pukul 07.00-15.00.

Shift siang : : pukul 15.00-pukul 23.00 atau pukul 14.00-23.00.

Shift malam : pukul 23.00-pukul 07.00 atau pukul 22.00-07.00.

Untuk shift di bar shift sore dimulai pukul 17.00-01.00.

Ada hotel yang mempunyai hari kerja 6 hari dan hari libur 1 hari, tetapi ada hotel yang mempunyai 5 hari kerja dengan 2 hari libur.

Dengan jadwal kerja yang tidak menentu, karena disesuaikan dengan jadwal, maka para karyawan wanita terutama yang sudah menikah dan yang mempunyai anak, harus membagi waktu dan konsentrasinya mengurus rumah tangga, mengurus anak, dan bekerja. Karena saat mereka masuk shift siang, mereka akan sampai di rumah tengah malam dimana anak dan suami sudah tidur. Dan mereka yang mendapat jadwal shift pagi, juga harus mengatur waktu karena mereka harus berangkat dari rumah pagi-pagi dan memastikan apakah sarapan untuk keluarga sudah siap sebelum mereka berangkat.

Di Indonesia, para wanita tidak diperbolehkan bekerja pada shift malam karena alasan keamanan. Hal ini disampaikan oleh Marhaeni (2011): "Adanya peraturan kepegawaian khusus bagi perempuan yang tidak dibolehkan bekerja pada shift malam hari, akan mengakibatkan perusahaan untuk mempekerjakan karyawan perempuan sesedikit mungkin.” Bagi pihak hotel, peraturan ini ditanggapi dengan mengatur penjadwalan agar para karyawan wanita mendapat shift pagi dan siang saja.

\section{Masalah Transportasi}

Bagi karyawan yang pulang dari shift siang, tentunya akan kesulitan jika hendak pulang bekerja karena pada tengah malam kendaraan umum sudah jarang dan membawa kendaraan pribadi bagi wanita yang pulang malam dianggap riskan. Untuk memberi perlindungan kepada karyawan, maka pihak hotel menyediakan kendaraan dinas untuk mengantar pulang para karyawan wanita dimana para karyawan yang hendak pulang diantar kendaraan dari hotel harus mendaftar di sekuriti pada saat mereka hendak mulai bekerja. Ada juga hotel yang tidak menyediakan kendaraan dinas, tetapi dengan memberi voucher taksi kepada karyawan wanita yang pulang malam. Jadi para karyawan ini juga terjamin keamanannya karena mereka akan mengambil taksi dari lobby hotel dimana perusahaan taksi ini sudah mempunyai kerjasama dengan hotel. Voucher taksi ini hanya bisa digunakan untuk perusahaan taksi tersebut dan untuk tanggal dimana mereka pulang malam hari.

Penjaminan keamanan terhadap karyawan wanita yang pulang malam ini sesuai dengan ucapan Menakertrans, Muhaimin,yang menegaskan perlunya perlindungan kepada pekerja perempuan, khususnya yang dipekerjakan pada malam hari. Jaminan keamanan melalui penyediaan petugas keamanan di tempat kerja, kamar mandi dengan penerangan yang layak, serta fasilitas antar-jemput bagi buruh perempuan adalah bentuk perhatian khusus dari pihak perusahaan. Perlindungan keamanan 
ini penting karena karyawan merupakan aset perusahaan, dimana mereka diharapkan bisa bekerja lagi pada keesokan harinya dengan baik.

\section{Perlindungan atau Keamanan}

Perlindungan terhadap karyawan wanita bukan hanya pada saat selesai bekerja, tetapi saat mereka menjalankan tugasnya. Karyawan wanita juga berhak mendapat perlindungan bebas dari diskriminasi dan pelecehan seksual baik yang mungkin terjadi dari rekan kerja ataupun dari tamu.

Dulu kala, ada pandangan negatif bagi wanita yang bekerja di hotel, yaitu pandangan bahwa mereka melakukan pekerjaan yang tidak terpuji dan bisa diajak kencan oleh tamu. Pandangan ini mungkin berkurang pada saat ini, walaupun mungkin masih ada image seperti ini di sebagian masyarakat. Hal ini juga disampaikan Marhaeni (2012): “Ada pekerjaan-pekerjaan yang dilakukan oleh perempuan dianggap pekerjaan yang tidak bermoral, misalnya pekerjaan yang dilakukan di malam hari, pekerjaan di industri perhotelan, pelayan tempat minum, yang tentunya merugikan perempuan. Hal ini tentulah tidak tepat karena wanita yang bekerja di perhotelan tidak bisa digeneralisasi bahwa mereka tidak bermoral.

Untuk menghindari diskriminasi dan pelecehan seksual, maka hotel membuat peraturan dan kampanye bahwa hotelnya menjalankan bisnisnya dengan etika yang baik. Rekan-rekan kerja juga harus mencipatakan kondisi yang kondusif agar tidak ada diskriminasi. Serta jika ada indikasi pelecehan seksual baik yang dilakukan oleh rekan kerja maupun oleh tamu, sudah ada kebijakan dari hotel yang melindungi karyawan perempuan.

Dalam hubungan kerja, tidak boleh ada perlakuan diskriminasi terhadap pekerja perempuan terutama dalam pemberian upah, tunjangan keluarga dan jaminan sosial, kesempatan mengikuti pelatihan serta promosi jabatan. Pemenuhan hak tersebut tidak boleh berlaku diskriminatif, kata Muhaimin seperti dikutip dari website http://menteri.depnakertrans.go.id/?show=news\&news_id=782.

\section{Problematika Karyawan Wanita yang Berhubungan dengan Kodratnya}

Muhaimin Iskandar, Menteri Tenaga Kerja dan Transmigrasi, mengatakan upaya perlindungan khusus kepada pekerja perempuan diperlukan sebagai salah satu bentuk untuk mewujudkan kesetaraan gender. Upaya perlindungan ini diberikan sesuai dengan kekhususan yang dimiliki kaum perempuan. Perusahaan-perusahaan harus memerhatikan berbagai keistimewaan yang khas yang menjadi hak dasar pekerja perempuan. Mereka memiliki hak khusus seperti hak cuti hamil, hak cuti melahirkan, hak cuti tertentu sebagai kodrat perempuan, kata Muhaimin.

\section{Cuti Haid}

Bagi wanita yang normal dan sehat, pada usia tertentu akan mengalami haid. Dalam praktiknya, banyak wanita yang sedang dalam masa haid tetap bekerja tanpa gangguan apapun. Akan tetapi, kalau keadaan fisiknya tidak memungkinkan, yang bersangkutan tidak dapat melakukan pekerjaan tersebut. Hal ini diatur dalam UU No. 1 tahun 1951, pasal 13 ayat 1 dinyatakan: Buruh wanita tidak boleh diwajibkan bekerja pada hari pertama dan hari kedua waktu haid. Pelaksaan dari ketentuan tersebut diatur dalam peraturan pemerintah No. 4 tahun 1951, pasal 1 sub pasal 1 ayat 2: dalam menjalankan aturan tersebut dalam UU No. 1 tahun 1951 pasal 13 ayat 1, maka pemberi kerja dianggap tidak mengetahui tentang keadaan haid dari pekerjanya, bila yang bersangkutan tidak memberitahukan hal itu kepadanya.

Problematika haid ini yang membedakan antara karyawan wanita dan pria. Dalam menjalankan tugas melayani tamu, fisik dan mood yang prima sangat diperlukan. Jika karyawan sedang dalam kondisi yang tidak prima, bisa jadi pelayanan yang diberikan ke tamu akan berpengaruh dan mungkin kurang maksimal. 
Seperti yang sudah disebutkan, mungkin bagi banyak wanita, masa haid ini tidak mengganggu sama sekali dalam mereka menjalankan pekerjaan. Akan tetapi bagi sebagian wanita, hari pertama dan hari kedua haid adalah masa yang tidak nyaman dan mungkin membuat kondisi fisik tidak prima. Jadi menurut undang-undang, jika memang mengalami kondisi yang membuat fisik tidak bisa bekerja saat hari pertama dan kedua haid, karyawan wanita berhak cuti.

Tentu hal ini harus dibicarakan dengan baik oleh karyawan dan atasannya. Karena dalam bagian front liner, jika kekurangan seorang karyawan secara mendadak, bisa memengaruhi operasional di divisi tersebut. Yang dikhawatirkan adalah hotel kekurangan karyawan pada hari itu sehingga tidak bisa melayani tamu secara maksimal.

Menurut I Putu Satyawira Marhaendra, ketua Federasi Serikat Pekerja Pariwisata Kabupaten Badung(http://www.cybertokoh.com/index.php?option=com_content\&task=view\&id=640\&Itemid=61 ): "Bisa dipahami jika dalam kondisi sakit, pekerja tidak bisa memberikan pelayanan secara optimal. Hal ini akan segera tampak di kalangan pekerja hotel di front line. Jika mereka tidak bekerja, tidak mengganggu pelayanan, sebab sudah bisa diantisipasi kapan mereka tidak bekerja berdasarkan siklus haid bulan-bulan sebelumnya, sehingga penggantinya sudah disiapkan." Persoalan-persoalan ketenagakerjaan yang terkait tenaga kerja perempuan seperti ini tidak luput dari perhatian Federasi Serikat Pekerja Pariwisata dan unit-unit kerja di tiap perusahaan. Di satu pihak hak tenaga kerja perempuan terpenuhi, di pihak lain jangan sampai mengganggu proses produksi.

\section{Cuti Hamil, Melahirkan dan Gugur Kandungan}

Bagi tenaga kerja wanita yang hamil, dilindungi oleh UU dalam pasal 13 ayat 2 dan ayat 3 yang menyatakan: "Buruh wanita harus diberi istirahat selama saru setengah bulan sebelum saatnya ia melahirkan menurut perhitungan dan satu setengah bulan setelah melahirkan anak atau gugur kandungan.”

Ketentuan tersebut dinyatakan berlaku dengan peraturan pemerintahan No. 4 tahun 1951 pasal 1 sub pasal 1 yang berbunyi: bagi tenaga kerja yang akan menggunakan hak cutinya diwajibkan mengajukan permohonan yang dilampiri surat keterangan dokter, bidan atau keduanya tidak ada, dapat dari pegawai pamong praja atau sederajatnya camat; permohonan diajukan selambatnya 10 hari sebelum waktu cuti mulai.

Cuti sebelum saatnya melahirkan dimungkinkan untuk diperpanjang apabila ada keterangan dokter yang menerangkan bahwa yang bersangkutan perlu mendapatkan istirahat untuk menjaga kehamilannya. Perpanjangan waktu istirahat sebelum melahirkan memungkinkan sampai selamalamanya tiga bulan. Bagi karyawan yang sedang hamil, maka biasanya ditempatkan di bagian yang tidak berhubungan melayani tamu langsung (back office area) ataupun ditempatkan di tempat yang membuat tidak perlu bergerak banyak.

Jika ia seorang receptionist, biasanya karyawan ini dipindah sementara ke bagian reservasi atau operator yang tidak perlu berdiri lama. Jika ia adalah waitress, sementara dipindah ke bagian order taker room service ataupun seorang staff di banquet office. Jika ia seorang chef di pastry atau kitchen, chef pastry mungkin dipindah ke bagian yang menjual toko roti. Untuk chef di kitchen mungkin dipindah ke bagian lain yang tidak terlalu berat sesuai kondisi hotel saat itu.

Dengan kondisi hamil, maka rekan-rekan kerja yang lain tidak boleh perlu membantu dan mempunyai pengertian yang tinggi bahwa rekan yang sedang hamil, ada kalanya tidak bisa secara maksimal karena tidak bisa bergerak cepat dan tidak boleh berdiri terlalu lama. Selain itu mungkin juga karyawan ini mengalami masa mual dan muntah yang mungkin mengganggu pekerjaan. 
Dan setelah melahirkan, mereka diberi kesempatan istirahat selama 1,5 bulan kecuali ada indikasi medis bahwa ia harus beristirahat lagi. Maka, harus ada komunikasi yang jelas dari karyawan ke pihak atasan, supaya para manajemen bisa mengatur langkah dalam menjalankan operasional hotel. Jika diperlukan, mungkin bisa mencari tenaga paruh waktu dalam mengisi kekosongan sementara ini.

\section{Kesempatan Menyusukan Anak}

Bagi tenaga kerja wanita yang masih menyusukan anak, harus diberi kesempatan sepatutnya untuk menyusukan anak. Dalam penjelaskan pasal 13 ayat 4 tersebut ditentukan bahwa dipikirkan oleh pemerintah kemungkinan mengadakan tempat penitipan anak. Satyawira juga menyebutkan Undangundang juga mengatur: "Pekerja/buruh perempuan yang anaknya masih menyusu harus diberi kesempatan sepatutnya untuk menyusui anaknya jika hal itu harus dilakukan selama waktu kerja" (Pasal 83).

Pasal 30 Peraturan Pemerintah Nomor 33 Tahun 2012: kantor pemerintah, swasta, dan pengelola sarana umum wajib menyediakan ruang menyusui dan memerah ASI. Sarana umum yang dimaksud di antaranya adalah fasilitas pelayanan kesehatan, hotel dan penginapan, tempat rekreasi, terminal bus, stasiun kereta, bandara, pelabuhan, pusat berbelanjaan, serta gedung olahraga. Selain membangun ruangan menyusui, pengelola kantor pemerintah, swasta, dan sarana umum juga wajib memberikan kesempatan kepada ibu yang bekerja untuk menyusui ASI eksklusif atau memerah ASI.

Tidak bisa dipungkiri, setelah melahirkan masih ada masa menyusui, yang artinya perhatian manajemen hotel tidak berhenti sampai cuti melahirkan saja. Pada masa menyusui, dimana para bayi tidak memungkinkan bertemu ibunya untuk menyusui langsung, biasanya para ibu harus memompa ASI dan disimpan di lemari pendingin agar ASI tidak rusak. "Saya juga menghimbau kepada para Kepala Dinas yang membidangi ketenagakerjaan di tingkat Provinsi maupun Kabupaten/Kota untuk dapat menggerakkan pihak Perusahaan agar terus mengusahakan fasilitas penunjang bagi buruh perempuan, seperti ruang laktasi atau menyusui bagi para ibu dan tempat penitipan anak”, ujar Muhaimin Iskandar.

Sampai saat ini, penulis belum pernah menemukan ada nursery room/ruang laktasi (ruangan untuk memompa dan menyimpan ASI) yang disediakan oleh pihak hotel. Tidak hanya di industri perhotelan, di banyak perkantoran dan pabrik, banyak perusahaan yang belum menyedian ruang laktasi bagi karyawan yang sedang menyusui. Saat ini para karyawan sangat kesulitan jika harus mencari tempat untuk memompa susu dan menyimpannya. Jika di hotel ada lemari pendingin, walaupun pendingin ini seharusnya digunakan untuk keperluan hotel, tetapi kadang-kadang dipakai untuk menitipkan sementara ASI mereka. Hal ini tidak baik, karena kemungkinan makanan yang disimpan di pendingin mengandung bakteri yang berbahaya terkontaminasi dalam ASI tersebut. Bapak Minarto selaku Direktur Bina Gizi Masyarakat Kementerian Kesehatan seperti dikutip dari website http://www.108csr.com/home/news.php?id=14653 mengatakan: "Sebenarnya tidak perlu mewah, hanya cukup ada tempat untuk duduk, cuci tangan dan ditutupi tirai, serta lemari es untuk menyimpan ASI."

Padahal pemberian ASI apalagi secara ekslusif sangat penting bagi pertumbuhan bayi tersebut dan dari pemberian ASI ekslusif juga membantu negara menciptakan manusia yang sehat. Selain itu juga perlu disepakati bersama bahwa ibu menyusui mungkin memerlukan waktu lain di luar waktu istirahatnya karena harus memompa ASI secara berkala. Jangan sampai para ibu ini kesulitan mendapat waktu untuk memompa ASI yang bahkan berujung pada pemecatan karyawan. 


\section{SIMPULAN}

Potensi wanita sebagai salah satu unsur dalam menunjang pembangunan terutama dalam bidang perhotelan tidak dapat disangkal lagi. Dengan kondisi seperti ini, tentunya pihak manajemen hotel harus semakin menghargai dan melindungi karyawan wanita dalam hal keselamatan dan pemenuhan kodratnya sebagai wanita. Sampai saat ini, pihak manajemen hotel sudah berusaha melindungi karyawan wanita dengan menyediakan transportasi bagi karyawan yang pulang malam. Hal ini merupakan komitmen yang baik dari hotel untuk terus memberikan perlindungan. Selain itu, dengan adanya komitmen untuk melindungi karyawan wanita dari pelecehan seksual dan diskriminasi, pihak hotel sudah menjalankan kewajibannya dan harus terus dipertahankan.

Saran-saran yang bisa dihasilkan dari analisis ini adalah sebagai berikut. Berhubungan dengan cuti haid, pelaksanaan ketentuan tidak bekerja karena merasakan sakit pada hari pertama dan kedua masa haid itu lebih jauh diatur dalam perjanjian kerja, peraturan perusahaan, atau perjanjian kerja bersama. Jadi, perlu ada kesepakatan dan aturan yang jelas dari pihak manajemen hotel mengenai cuti haid ini. Hal ini tidak dimaksudkan untuk memanjakan karyawan, tetapi untuk menghargai kodrat wanita yang alami terjadi. Kemudian, penyediaan ruang laktasi bagi karyawan wanita yang menyusui adalah mutlak karena sudah diatur dalam Peraturan Pemerintah. Seharusnya tidak menjadi alasan bagi manajemen untuk tidak menyediakan ruang laktasi. Ruang laktasi tidak harus mewah tetapi sesuai standar. Steril saja sudah cukup.

Lebih lanjut, pengaturan jam kerja dalam hal pemberian izin untuk memompa ASI. Mengingat sifat industri perhotelan adalah pelayanan dan sifatnya terus menerus, maka perlu diatur lebih lanjut mengenai pemberian izin bagi karyawan yang sedang dalam masa menyusui untuk memompa ASI. Hal ini dimaksudkan agar ibu menyusui ini tetap bisa nyaman bekerja dan ASI juga bisa lancar. Salah satu hal yang membuat ASI tidak lancar adalah pikiran stres yang dialami para ibu menyusui. Tujuan dengan semakin diperhatikan kodrat wanita bukan bermaksud untuk membuat karyawan wanita menjadi lebih spesial. Akan tetapi, ada hal-hal dasar yang sudah menjadi kodratnya dan harus dipenuhi. Jika hak-hak dasar ini sudah dipenuhi, ini merupakan suatu reward bagi karyawan wanita agar mereka terus dapat bekerja dengan nyaman dan tenang sehingga produktivitas karyawan tetap terjaga dan loyalitas karyawan juga makin tinggi. Hal ini disampaikan juga oleh Menteri Tenaga Kerja dan transmigrasi, Muhaimin Iskandar: "Berbagai bentuk perlindungan dan faktor penunjang kenyamanan bekerja bagi pekerja perempuan akan mengarah kepada peningkatan produktivitas kerja."

\section{DAFTAR PUSTAKA}

ARD. (29 Maret 2010). Hak Pekerja Perempuan Cuti Haid dan Cuti Hamil. Diakses dari http://www.cybertokoh.com/index.php?option=com_content\&task=view\&id=640\&Itemid=61

Badan Pusat Statistik. (2012). Diakses dari http://bps.go.id.

Biografi Tokoh Dunia. (Januari 2009). Biografi R. A. Kartini. Diakses dari http://kolombiografi.blogspot.com/2009/01/biografi-ra-kartini.html

Depnakertrans. (21 Desember 2011). Menakertrans : Tidak Boleh Ada Diskriminasi Terhadap Pekerja Perempuan. Diakses dari http://menteri.depnakertrans.go.id/?show=news\&news_id=782. 
Kalsum. Diakses dari http://repository.usu.ac.id/bitstream/123456789/3754/1/fkm-kalsum.pdf

Marhaeni, A. A .I. N. (2011). Perkembangan Studi Perempuan, Kritik, dan Gagasan Sebuah Perspektif untuk Studi Gender ke Depan. Ejournal Universitas Udayana.

http://www.108csr.com/home/news.php?id=14653. 